\title{
Control Techniques for the Cascaded and Cross-switched Multilevel Inverter - A Comparison
}

\author{
Sameera Shaik $^{1 *}$, Suresh Kumar Tummala ${ }^{2}$ D Srinivasa Rao $^{3}$ \\ ${ }^{1,2,3}$ Department of Electrical and Electronics Engineering. Gokaraju Rangaraju Institute of Engineering \& Technology, Hyderabad, India
}

\begin{abstract}
Nowadays, the multilevel inverter has gained huge attention and has become more popularized in high voltage and high-power applications with low harmonics. As the number of output voltage increases, the harmonic content of the output voltage waveform decreases. In this paper, a comparison of cascaded $\mathrm{H}-$ bridge and cross-switched multilevel inverters for 7, 9, 15, 21 levels will be carried out. The different control techniques that will be used for carrying out comparisons are space vector pulse width modulation (SPVPWM), sinusoidal pulse width modulation (SPWM), and third harmonic injection pulse width modulation (THI-PWM) respectively. Here, the seven-level inverter is discussed mainly and can be extended to any number of levels.
\end{abstract}

Keywords-Multilevel Inverter, Total Harmonic Distortion, Sinusoidal Pulse Width Modulation, Third Harmonic Injection Pulse Width Modulation, Cross-Connected, Total Standing Voltage

\section{Nomenclature}

\begin{tabular}{|c|l|}
\hline Abbreviation & \multicolumn{1}{|c|}{ Explanation } \\
\hline $\mathrm{V}_{\text {ref2 }}$ & $\begin{array}{l}\text { Reference voltage vector of a two-level } \\
\text { hexagon }\end{array}$ \\
\hline $\mathrm{V}_{\text {ref4 }}$ & $\begin{array}{l}\text { Reference voltage vector of four-level } \\
\text { hexagon }\end{array}$ \\
\hline $\mathrm{V}_{\mathrm{ndc}}$ & Number of DC voltage sources \\
\hline $\mathrm{V}(\mathrm{t})$ & $\begin{array}{l}\text { The output voltage of the multilevel } \\
\text { inverter (MLI) }\end{array}$ \\
\hline $\mathrm{A}$ & Real axis \\
\hline $\mathrm{N}_{\mathrm{d}}$ & $\begin{array}{l}\text { Number of switches in the current path } \\
\text { respectively. }\end{array}$ \\
\hline $\mathrm{B}$ & Imaginary axis \\
\hline $\mathrm{a}_{0}, \mathrm{a}_{\mathrm{n}}, \mathrm{b}_{\mathrm{n}}$ & $\begin{array}{l}\text { These are the coefficients of the Fourier } \\
\text { transform }\end{array}$ \\
\hline $\mathrm{O}$ & Angle made by $\mathrm{V}_{\text {ref }}$ vector \\
\hline $\mathrm{O}_{2}$ & Angle made by $\mathrm{V}_{\text {ref2 vector }}$ \\
\hline $\mathrm{O}_{4}$ & Angle made by $\mathrm{V}_{\text {re4 }}$ vector \\
\hline $\mathrm{V}_{\mathrm{ma}}$ & The modulation signal \\
\hline $\mathrm{f}_{\mathrm{m}}$ & Modulating wave's peak frequency \\
\hline $\mathrm{F}$ & $\begin{array}{l}\text { Fundamental output frequency of the } \\
\text { inverter }\end{array}$ \\
\hline $\mathrm{f}_{\mathrm{cr}}$ & Carrier wave's peak frequency, \\
\hline $\mathrm{V}_{\mathrm{m}}$ & Reference signal peak amplitude \\
\hline $\mathrm{V}_{\mathrm{cr}}$ & $\begin{array}{l}\text { Carrier signal peak amplitude respectively, } \\
\text { ma is the amplitude modulation index }\end{array}$ \\
\hline $\mathrm{V}_{\mathrm{ref}}$ & Reference voltage vector \\
\hline
\end{tabular}

* Corresponding author: sameera.250@gmail.com

\section{Introduction}

Multilevel inverters have become more focused and popularized in the past few decades. Multilevel Inverter is a power electronic device that can be used for high/medium voltage and power conditions with advantages of low harmonics, lower $\mathrm{dv} / \mathrm{dt}$ stress on power electronic devices, lower device ratings, and reduced switching frequencies. In addition to the given advantages, some other advantages are low Total Harmonic Distortion (THD), efficiency, reliability, etc. Because of these advantages they are considered as proven technology and hence entered industry successfully. A three-level multilevel inverter was the first multilevel inverter that was introduced in 1975.

The different conventional topologies [1-7] of multilevel inverters are Neutral Point Clamped (NPC), Flying Capacitor (FC), and cascaded H-Bridge inverters (CHB). These regular geographies enjoy their benefits and weaknesses, however the fundamental downside of these three geographies is the requirement for high-power electronic parts, with an increment in the quantity of levels. This importantly builds the expense and intricacy of staggered inverters. In view of these disadvantages analysts have thought of new geographies of staggered inverters with less exchanging parts. Alongside presenting novel staggered inverter geographies, various strategies for control procedures for staggered inverters have likewise been presented. These control strategies can likewise be called adjustment methods which are characterized into two sorts. They are high recurrence and low-recurrence adjustment. Low-frequency modulation techniques cannot be applied for high power applications even though having better harmonic profiles. These are classified as space vector and selective harmonic elimination. High-frequency modulation can be 
further divided into Sinusoidal Pulse Width Modulation (SPWM) and Space Vector Pulse Width Modulation (SVPWM) techniques. Because of all these factors, this paper proposes a comparison of the seven-level cascaded and cross-bridge multilevel inverter using different control techniques which are Sinusoidal Pulse Width Modulation [2,5,6,16,17], Space Vector Pulse Width Modulation [1,3], and Third Harmonic Injection Pulse Width Modulation respectively [4].

\section{Cascaded H-Bridge Topology}

Fig.1 shows a conventional stage seven-level customary cascade H-bridge geography $[11,12,13]$. The seven-level cascade H-bridge staggered inverter comprises of three series-associated single-stage H-spans per stage to which a secluded DC source is available for every $\mathrm{H}$-connect. The fundamental downside of cascade $\mathrm{H}$-connect is the requirement for disconnected force hotspots for each level and stage. The secluded design of indistinguishable $\mathrm{H}$-bridge is a reassuring element. As every $\mathrm{H}$-connect is taken care of by a similar worth of Dc voltage, it is known as a balanced fell $\mathrm{H}$-bridge staggered inverter. Every $\mathrm{H}$-bridge can produce three degrees of yield voltage, which are $+\mathrm{V}_{\mathrm{dc}}, 0,-\mathrm{V}_{\mathrm{dc}}$. The exchanging design is displayed in Table 1 and the yield voltage of the seven-level inverter can be found in Fig. 2. The proposed geography is customary and can be stretched out to any staggered inverter by utilizing the accompanying formulae.

1. The number of levels in line-to-line voltage waveform is $\mathrm{k}=2 \mathrm{~N}-1$

2. Per phase number of capacitors or isolated supplies are $\mathrm{N}_{\text {cap }}=(\mathrm{N}-1) / 2$

Advantages of cascaded H-bridge are:

1. The number of DC sources required is half the number of output voltage levels.

2. The manufacturing process is quicker and cheaper.

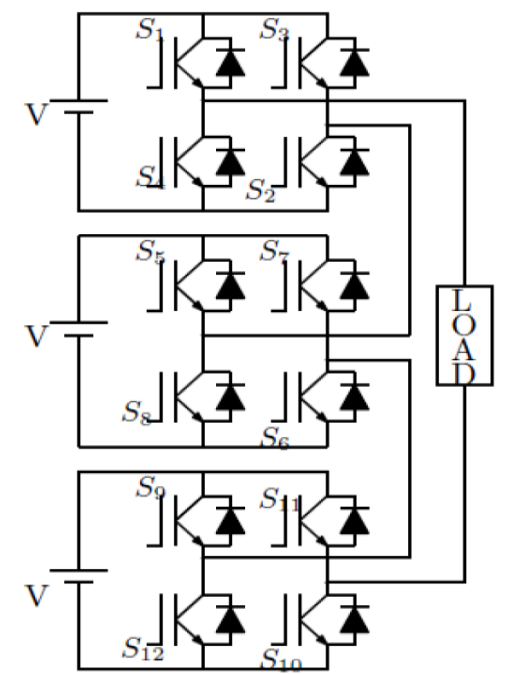

Fig. 1. Conventional cascaded 7 level inverter

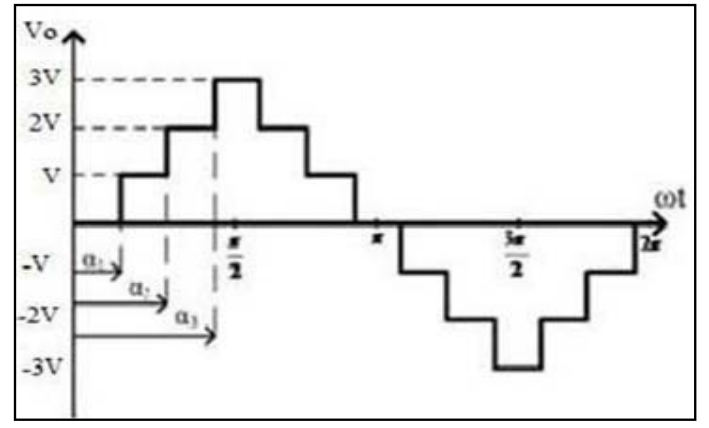

Fig. 2. The output voltage waveform of seven-level inverter [5]

Table 1. Switching sequence of seven-level inverter

\begin{tabular}{|c|c|c|c|c|c|c|c|}
\hline $\mathbf{V}_{\mathbf{0}}$ & $+\mathbf{V}$ & $\mathbf{+ 2 V}$ & $\mathbf{+ 3 V}$ & $\mathbf{0}$ & $\mathbf{- V}$ & $\mathbf{- 2 V}$ & $\mathbf{- 3 V}$ \\
\hline $\mathbf{S}_{\mathbf{1}}$ & 1 & 1 & 1 & 0 & 0 & 0 & 0 \\
\hline $\mathbf{S}_{\mathbf{2}}$ & 1 & 1 & 1 & 1 & 0 & 0 & 0 \\
\hline $\mathbf{S}_{\mathbf{3}}$ & 0 & 0 & 0 & 0 & 1 & 1 & 1 \\
\hline $\mathbf{S}_{\mathbf{4}}$ & 0 & 0 & 0 & 1 & 1 & 1 & 1 \\
\hline $\mathbf{S}_{\mathbf{5}}$ & 0 & 1 & 1 & 0 & 0 & 0 & 0 \\
\hline $\mathbf{S}_{\mathbf{6}}$ & 1 & 1 & 1 & 1 & 1 & 0 & 0 \\
\hline $\mathbf{S}_{\mathbf{7}}$ & 0 & 0 & 0 & 0 & 0 & 1 & 1 \\
\hline $\mathbf{S}_{\mathbf{8}}$ & 1 & 0 & 0 & 1 & 1 & 1 & 1 \\
\hline $\mathbf{S}_{\mathbf{9}}$ & 0 & 0 & 1 & 0 & 0 & 0 & 0 \\
\hline $\mathbf{S}_{\mathbf{1 0}}$ & 1 & 1 & 1 & 1 & 1 & 1 & 0 \\
\hline $\mathbf{S}_{\mathbf{1 1}}$ & 0 & 0 & 0 & 0 & 0 & 0 & 1 \\
\hline $\mathbf{S}_{\mathbf{1 2}}$ & 1 & 1 & 0 & 1 & 1 & 0 & 1 \\
\hline
\end{tabular}

\subsection{Control of Cascaded H-Bridge Inverter using Sinusoidal Pulse Width Modulation (SPWM)}

The sinusoidal pulse width modulation technique $[8,9,14]$ is a simple modulation technique used for harmonic reduction in inverters. In this technique, the pulse magnitude will be constant, and the pulse width is changed. Here, a reference wave is compared with a carrier wave and generates gate pulses. For this, a pure sine wave (reference) is compared with a triangular wave (carrier). The fundamental frequency is taken for the sine wave, and more than the fundamental frequency can be taken for the carrier wave. If the number of levels is $m$, then $(\mathrm{m}-1)$ triangular carrier waves are required. So, a seven-level inverter requires six carrier waves.

Two important parameters are defined in modulation techniques:

1. The frequency ratio $m_{f}=\frac{f_{c r}}{f_{m}}$

2. Amplitude modulation index $m_{a}=\frac{V_{m}}{V_{c r}(m-1)}$

The fundamental frequency component in the inverter output voltage can be controlled by the amplitude modulation index. Where $f_{m}$ is the modulating wave's peak frequency, $f_{c r}$ is the carrier wave's peak frequency, $V_{m}$ is the reference signal peak amplitude and $V_{c r}$ is carrier signal peak amplitude respectively. The amplitude modulation index $m_{a}$ is usually adjusted by varying $V_{m}$ 
and keeping $V_{c r}$ fixed. The frequency of the reference signal determines inverter output frequency and its peak amplitude controls modulation index and in turn RMS output voltage. The SPWM scheme used here is level shifted in phase disposition (IPD) as it has a lower harmonic profile compared to other conventional techniques. The gating pulses for the switches $S_{1}, S_{2}$ are provided by carrier waves $V_{c r 1}$ and $V_{c r 1-}$, the innermost carrier pair $V_{c r 3}$ and $V_{c r 3-}$ generate pulses for switches $\mathrm{S}_{9} \& \mathrm{~S}_{11}$. The remaining carrier waves $V_{c r 2}$ and $V_{c r 2-}$ generate gating pulses for $\mathrm{S}_{5} \& \mathrm{~S}_{7}$. Fig.3 shows level-shifted PWM for a seven-level cascaded H-bridge inverter. The switches $\mathrm{S}_{1}, \mathrm{~S}_{5}, \mathrm{~S}_{9}$ are turned on for the carrier waves above zero reference when modulating signal $V_{m A}$ is higher than carrier waves, and the switches $\mathrm{S}_{3}, \mathrm{~S}_{7} \& \mathrm{~S}_{11}$ are turned on for the carrier waves below the zero reference when modulating wave $V_{m A}$ is lower than carrier waves.
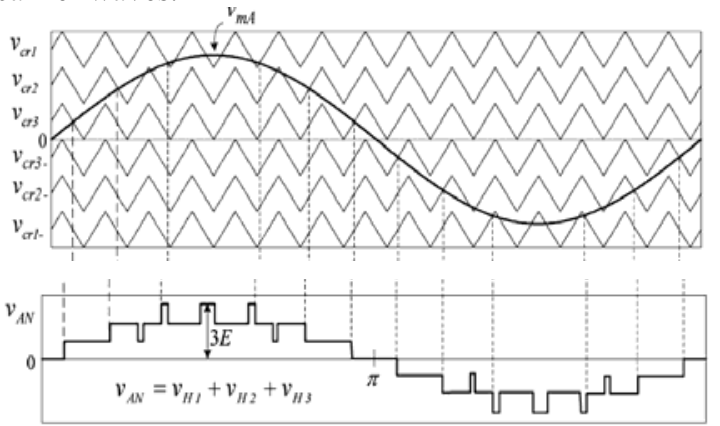

Fig. 3. Level-shifted PWM for a seven-level CHB inverter $\left(m_{f}\right.$ $=15, m_{a}=0.8, f_{m}=60 \mathrm{~Hz}$, and $f_{c r}=900 \mathrm{~Hz}$ ).

The results can be seen in Table 5, and the fundamental output voltage can be seen in Fig. 8(b) \& 9(b) for various modulation indices.

\subsection{Control of Cascaded $\mathrm{H}$-Bridge using Space Vector Pulse Width Modulation (SVPWM)}

The conventional 7-level space vector pulse width modulation (SVPWM) has a total of 216 two-level hexagons. As high quantities of triangles are included, the execution of this technique is exceptionally intricate in seven-level inverter. Thus, an improved on SVPWM method is utilized in this paper which is known as a further worked on space vector adjustment strategy (FSSVM) $[3,11,12,13]$ which is simpler contrasted with a regular procedure. By utilizing this method, the intricacy and exertion of the seven-level SVPWM become equivalent to the five-level SVPWM procedure. Here at first seven-level space vector chart is settled into six fourlevel hexagons and afterward every four-level hexagon into seven two-level hexagons. In this manner the all-out two-level hexagons to be considered here are just 42 . The space vectors incorporate fixed vectors and there is one turning vector $V_{\text {ref }}$ which pivots at a speed of $\omega=2 \pi f$ in space, where $f$ is the central yield recurrence of the inverter. $\mathrm{V}_{\text {ref }}$ is known as a kind of perspective vector. For the ordinary activity of the inverter, the extent of $V_{\text {ref }}$ relies on the regulation file, which goes from zero to one. By using the stationary vectors available, the $V_{\text {ref }}$ vector is synthesized as closely as possible, which is the basic principle of space vector pulse width modulation. By identifying the triangle in which the tip of $\mathrm{V}_{\text {ref }}$ lies we can synthesize $V_{\text {ref }}$ conventionally. "Nearest Three Vectors" (NTVs) are formed by the vertices of this triangle for $\mathrm{V}_{\text {ref }}$ and it is then synthesized by using these three vectors. After every sampling period $\left(t_{s}\right)$ this operation is repeated.

In the FSSVM technique, the space vector diagram is initially resolved into six four-level hexagons. Along $0^{\circ}$ axis the center of the first four-level hexagon lies, and each subsequent hexagon center is shifted by $60^{\circ}$. There is overlapping between adjacent hexagons as shown in Fig. 4. Depending upon the angle ' $\Theta$ 'of the original reference vector $V_{\text {ref }}$ of conventional space vector diagram, the appropriate four-level hexagons are selected which is shown in Table 2.

After the selection of a four-level hexagon, a new reference vector $V_{\text {ref4 }}$ is generated at the center of the four-level hexagon. The tip of $\mathrm{V}_{\text {ref4 }}$ coincides with the tip of Vref and both can b related as follows:

$$
\begin{aligned}
& V_{4 \alpha}=V_{7 \alpha}-2 E \\
& V_{4 \beta}=V_{7 \beta}
\end{aligned}
$$
and $V_{7 \alpha}, V_{7 \beta}, V_{4 \alpha}, V_{4 \beta}$ are components 0 respectively. Table 3 shows the computation of $V_{\text {ref4 }}$ for all the six four-level hexagons. The range of modulation index for the vector $V_{\text {ref4 }}$ is from zero to unity and an angle $\Theta_{4}$ ranging from zero to $2 \pi$.

The following stage is to determine these four-level hexagons into 42 two-level hexagons. These two-level hexagons are partitioned into two kinds. They are internal hexagon $(\mathrm{IH})$ and outer hexagon $(\mathrm{OH})$. Here every fourlevel hexagon is settled into seven two-level hexagons. Contingent upon the point and extent of the $\mathrm{V}_{\text {ref4 }}$ vector, the determination of two-level hexagons is done and is displayed in Table 4. The span of encompassing circle is $2 \mathrm{E} / 3$ for a two-level hexagon. Subsequently if the extent of $\mathrm{V}_{\text {ref4 }}$ is not exactly or equivalent to $2 \mathrm{E} / 3$ then the internal hexagon is chosen and assuming the size of $\mathrm{V}_{\text {ref4 }}$ is more noteworthy than $2 \mathrm{E} / 3$ one of the external hexagons is chosen which can be displayed in Table 4 . The vector $V_{\text {ref } 4}$ beginning is equivalent to the two-level reference vector beginning when the inward hexagon is chosen. Nonetheless, another reference vector $V_{\text {ref2 }}$ should be created when the external two-level hexagon is chosen.

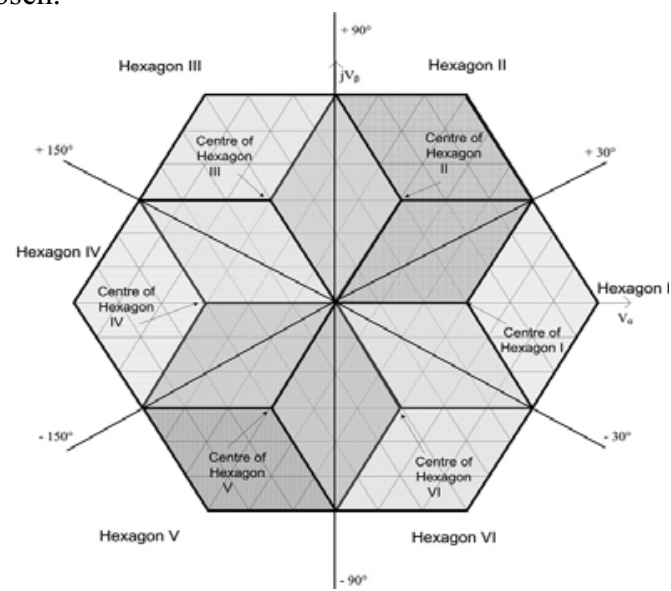

Fig. 4. Division of seven-level SVD into six four-level hexagons [3] 
The modulation index $\left(m_{a}\right)$ is defined as the maximum value $m_{a}=1$, to the maximum radius of the circle that can be inserted in the space vector diagram, this can be seen in Fig. 6. When the dark portion of the space vector diagram isn't included then six outer hexagons $(\mathrm{OH})$ are considered for $m_{a}=1$ and all the 42 two-level hexagons are included in the space vector diagram

Table 2. Selection of four-level hexagon

\begin{tabular}{|c|c|}
\hline Hexagon number & Range of $\boldsymbol{\Theta}$ \\
\hline I & $-30^{0}$ to $+30^{0}$ \\
\hline II & $+30^{0}$ to $+90^{0}$ \\
\hline III & $+90^{0}$ to $+150^{0}$ \\
\hline IV & $+150^{0}$ to $-150^{0}$ \\
\hline V & $-150^{0}$ to $-90^{0}$ \\
\hline VI & $-90^{0}$ to $-30^{0}$ \\
\hline
\end{tabular}

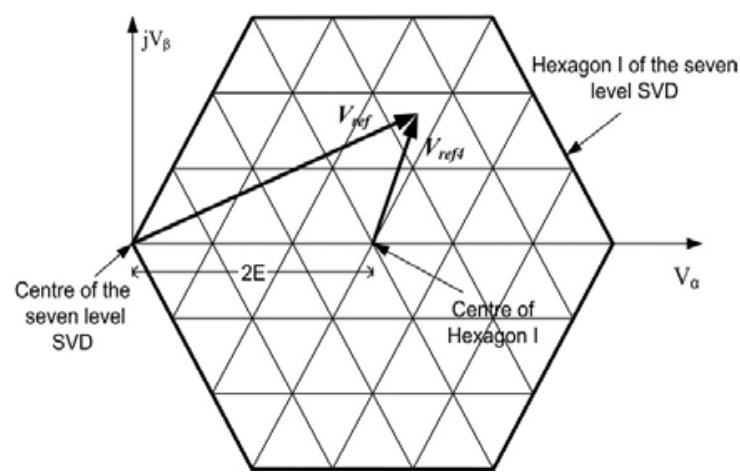

Fig. 5. Four-level hexagon I [3]

Table 3. Computation of $\mathrm{V}_{\text {ref4 }}$ from $\mathrm{V}_{\text {ref }}$

\begin{tabular}{|c|c|c|}
\hline Hexagon & $\mathbf{V}_{4 \alpha}$ & $\mathbf{V}_{4 \beta}$ \\
\hline $\mathbf{I}$ & $\mathrm{V}_{7 \alpha}-2 \mathrm{E}$ & $\mathrm{V}_{7 \beta}$ \\
\hline II & $\mathrm{V}_{7 \alpha}-2 \mathrm{E} \cos \frac{\pi}{3}$ & $\mathrm{~V}_{7 \beta}-2 \mathrm{E} \sin \frac{\pi}{3}$ \\
\hline III & $\mathrm{V}_{7 \alpha}-2 \mathrm{E} \cos \frac{2 \pi}{3}$ & $\mathrm{~V}_{7 \beta}-2 \mathrm{E} \sin \frac{2 \pi}{3}$ \\
\hline IV & $\mathrm{V}_{7 \alpha}+2 \mathrm{E}$ & $\mathrm{V}_{7 \beta}$ \\
\hline $\mathbf{V}$ & $\mathrm{V}_{7 \alpha}-2 \mathrm{E} \cos \frac{4 \pi}{3}$ & $\mathrm{~V}_{7 \beta}-2 \mathrm{E} \sin \frac{4 \pi}{3}$ \\
\hline VI & $\mathrm{V}_{7 \alpha}-2 \mathrm{E} \cos \frac{5 \pi}{3}$ & $\mathrm{~V}_{7 \beta}-2 \mathrm{E} \sin \frac{5 \pi}{3}$ \\
\hline
\end{tabular}

Table 4 describes the selection of particular two-level hexagons which depend on the magnitude and angle of the reference vector $V_{\text {ref4. }}$. Where $V_{\text {ref4 }}$ is the reference voltage of a four-level hexagon. After the selection of a two-level hexagon, calculation of dwell time and selection of switching sequence is carried out to give appropriate gate pulses to the proposed inverter by using the basic principle of two-level SVPWM respectively. The vectors $\mathrm{V}_{\text {ref2 }}$ and $\mathrm{V}_{\text {ref4 }}$ are related as follows:

$$
\begin{aligned}
& V_{2 \alpha}=V_{4 \alpha}-\frac{4 E}{3} \\
& V_{2 \beta}=V_{4 \beta}
\end{aligned}
$$

In this technique, the complexity is reduced but as a result, total harmonic distortion (THD) is increased for the modulation index $m_{a 4}>0.774$ of a four-level space vector diagram. For $m_{a 4}<0.774$ no part of the space vector diagram is left untouched and if $\mathrm{V}_{\text {ref4 }}$ lies in the dark unattended part then one of the outer hexagons is selected depending on the angle $\Theta_{4}$ of $V_{\text {ref4 }}$. Thus a new reference vector $V_{\text {ref2 }}$ is generated with its origin at the center of the two-level hexagon and thus depending on the angle of $\mathrm{V}_{\text {ref2, }}$, the appropriate sector will be selected and the SVPWM technique is carried out. The results can be seen in Table 5 , and the fundamental output voltage can be seen in Fig. 8(a) \& 9(a) for various modulation indices.

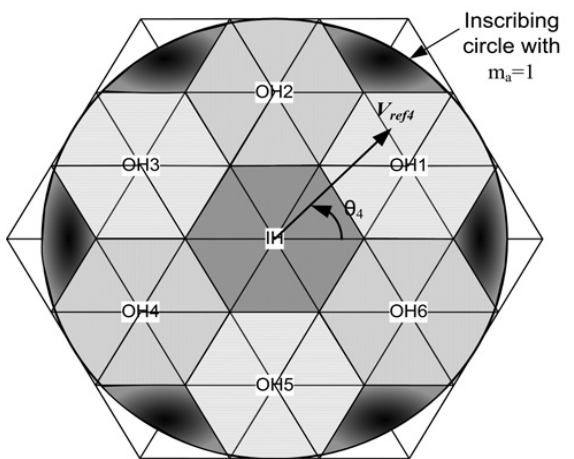

Fig. 6. Four-level SVD with inscribing circle for $m_{a}=1[3]$

\begin{tabular}{|c|c|c|}
\hline Two-level hexagon & Magnitude of $V_{\text {ref4 }}$ & Angle $\Theta_{4}$ of $V_{\text {ref4 }}$ \\
\hline $\mathrm{IH}$ & $\leq 2 E / 3$ & - \\
\hline OH1 & \multirow{6}{*}{$\geq 2 E / 3$} & $0^{0}$ to $60^{0}$ \\
\hline $\mathrm{OH} 2$ & & $60^{0}$ to $120^{0}$ \\
\hline $\mathrm{OH} 3$ & & $120^{\circ}$ to $180^{\circ}$ \\
\hline $\mathrm{OH} 4$ & & $-180^{\circ}$ to $-120^{0}$ \\
\hline OH5 & & $-120^{0}$ to $-60^{0}$ \\
\hline OH6 & & $-60^{0}$ to $-0^{0}$ \\
\hline
\end{tabular}

Table 4. Selection of a two-level hexagon in FSSVM technique

\subsection{Control of Cascaded H-Bridge using Third- Harmonic Injection Pulse Width Modulation (THIPWM)}

The sinusoidal pulse width balance procedure is not difficult to execute just as to comprehend. However, the fundamental disadvantage of this strategy is, it can't use the whole accessible DC transport supply voltage and subsequently this technique approaches less of the greatest attainable yield voltage. Along these lines, a third consonant infusion beat width adjustment procedure $[4,11,12,13]$ is acquainted with defeat this issue. In this technique, by adding a third consonant sign in a lowrecurrence sinusoidal reference signal we can accomplish the abundancy expansion in yield voltage waveform. The expansion of third music implies that in one pattern of a sinusoidal wave, three patterns of music will finish. The consequence of the expansion of the third symphonious and basic consonant is less in sufficiency than the key consonant. This method helps the inverter in its performance enhancement. Fig. 8 shows the fundamental voltage $\left(V_{m}\right)$, third harmonic content $\left(\frac{V_{m}}{n}\right)$, and the modulation signal $V_{m a}$. In this paper, a basic third harmonic injection pulse width modulation is carried out 
for a seven-level inverter and The results can be seen in Table 5, and the fundamental output voltage can be seen in Fig. 8(c)\&9(c) for various modulation indices.

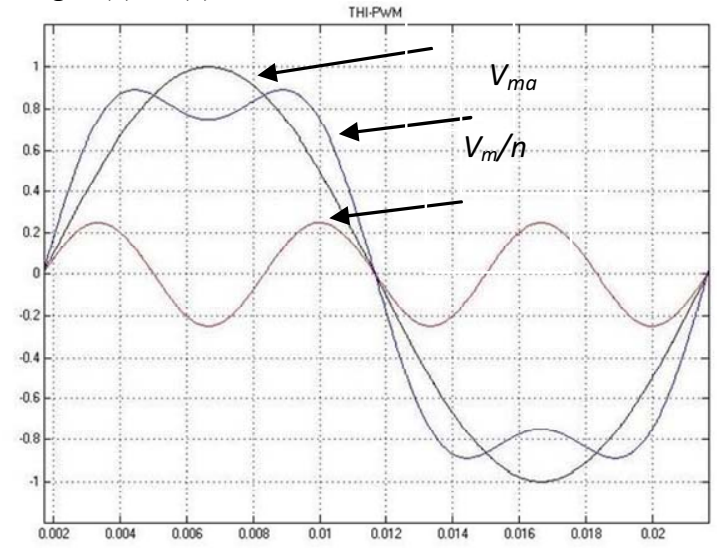

Fig. 7(a)
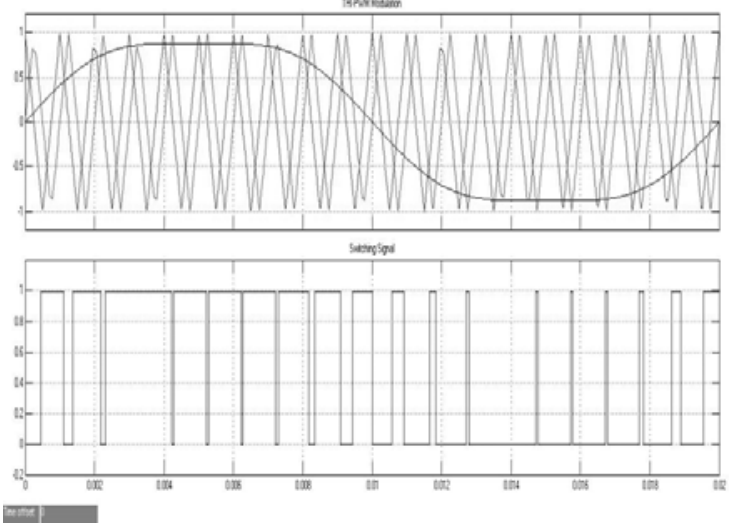

Fig. 7(b)

Fig.7. Third Harmonic Injection pulse width modulation [4] a) generating third harmonic injected modulating signal, b) multicarrier and modulating signals utilized in generating switching signals

\subsection{Comparison of Control Techniques for Cascaded H-Bridge}

The advantages of the space vector pulse width modulation technique over sinusoidal pulse width modulation are that it provides more fundamental output voltage also is flexible for the design of switching patterns and is better suited for digital implementation. Thus, space vector pulse width modulation technique is considered a popular choice for industrial applications. The fundamental component of output voltage and Total Harmonic Distortion (THD) obtained in the space vector pulse width modulation scheme is greater than the sinusoidal pulse width modulation scheme. It is better to use the third harmonic injection pulse width modulation scheme if the sole purpose is the total harmonic distortion reduction. As no FSSVPWM or SPWM can compare with THI-PWM as far as total harmonic distortion is dealt with. For modulation index $m_{a}<0.2$ or $m_{a}=0.2$, the FSSVPWM shows remarkable improvement over SPWM and THIPWM schemes. This is useful in cases where the inverter is sometimes required to function at low modulation indices. The results can be seen in Table 3, and fundamental output voltages for the three discussed control techniques can be seen in Fig. $8 \& 9$ for various modulation indices.

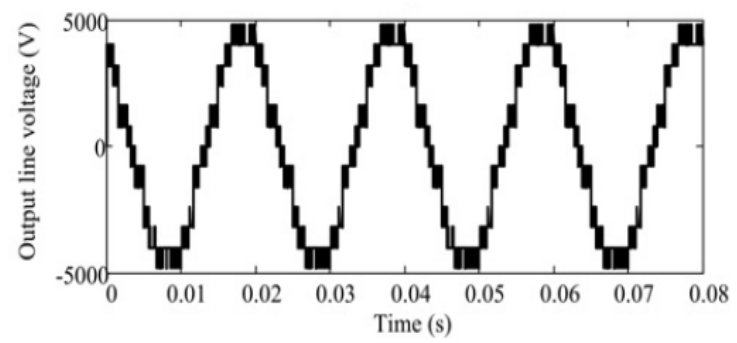

Fig. 8(a)

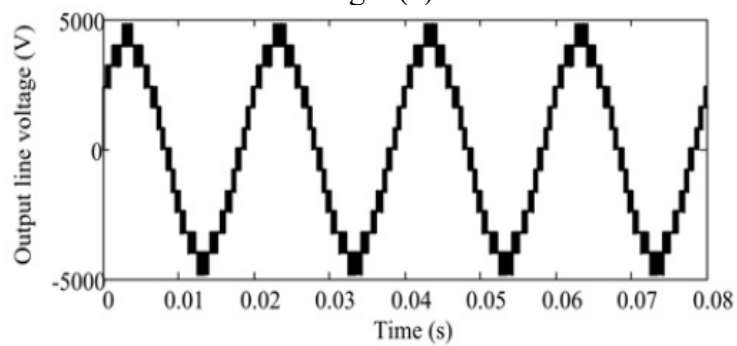

Fig. 8(b)

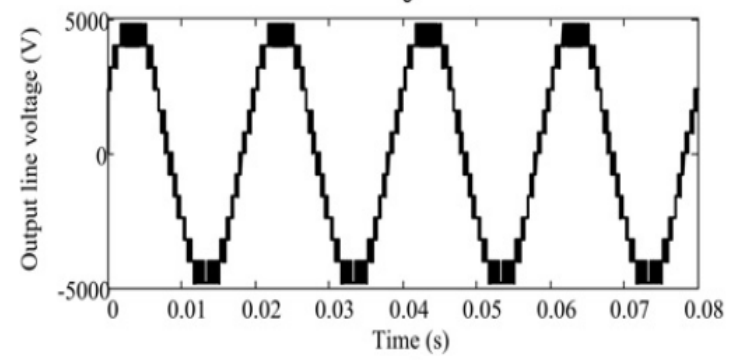

Fig. 8(c)

Fig. 8. Output line voltage waveforms at ma $=1[3]$ for a FSSVPWM

b SPWM and

c THI technique

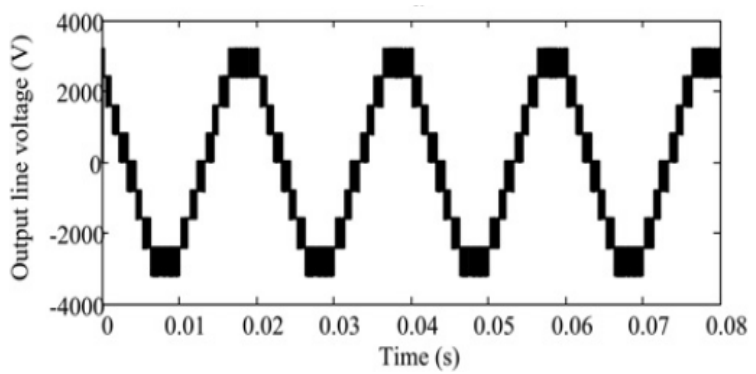

Fig. 9(a)

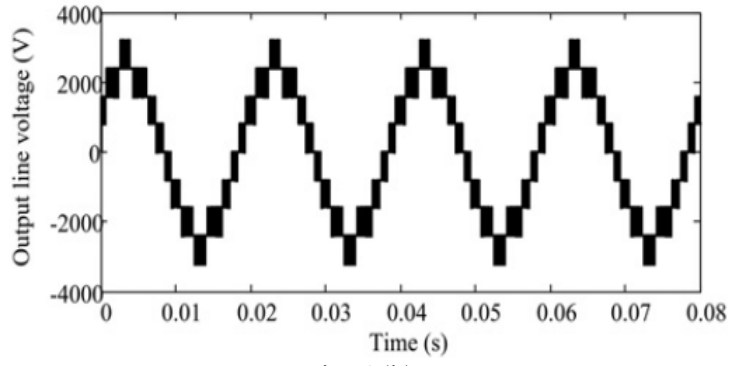

Fig. 9(b) 


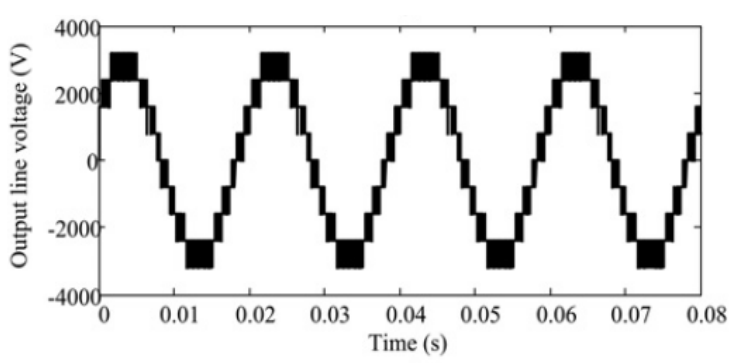

Fig. 9 (c)

Fig. 9. Output line voltage waveforms at $m_{a}=0.6$ [3] for a FSSVM

b SPWM and

c THI technique

Table 5. THD and peak value of the fundamental component $\left(\mathrm{V}_{1 \mathrm{~m}}\right)$ of output line voltage

\begin{tabular}{|c|c|c|c|c|}
\hline $\begin{array}{c}\text { Modulation } \\
\text { Technique }\end{array}$ & & FSSVPWM & SPWM & $\begin{array}{c}\text { THI- } \\
\text { PWM }\end{array}$ \\
\hline $\boldsymbol{m}_{\boldsymbol{a}}=\mathbf{1 . 0}$ & $\mathrm{THD}, \%$ & 16.36 & 10.62 & 9.16 \\
& $\mathrm{~V}_{1 \mathrm{~m}, \mathrm{~V}}$ & 4631 & 4158 & 4801 \\
\hline $\boldsymbol{m}_{\boldsymbol{a}}=\mathbf{0 . 8}$ & $\mathrm{THD}, \%$ & 15.77 & 13.33 & 12.32 \\
& $\mathrm{~V}_{1 \mathrm{~m}}, \mathrm{~V}$ & 3764 & 3325 & 3841 \\
\hline \multirow{2}{*}{$\boldsymbol{m}_{\boldsymbol{a}}=\mathbf{0 . 6}$} & $\mathrm{THD}, \%$ & 19.81 & 17.26 & 16.66 \\
& $\mathrm{~V}_{1 \mathrm{~m}}, \mathrm{~V}$ & 2892 & 2492 & 2879 \\
\hline \multirow{2}{*}{$\boldsymbol{m}_{\boldsymbol{a}}=\mathbf{0 . 4}$} & $\mathrm{THD}, \%$ & 30.29 & 25.55 & 24.37 \\
& $\mathrm{~V} 1 \mathrm{~m}, \mathrm{~V}$ & 2013 & 1662 & 1918 \\
\hline \multirow{2}{*}{$\boldsymbol{m}_{\boldsymbol{a}}=\mathbf{0 . 2}$} & $\mathrm{THD}, \%$ & 39.4 & 49.13 & 44.61 \\
& $\mathrm{~V} 1 \mathrm{~m}, \mathrm{~V}$ & 1405 & 831.9 & 961.3 \\
\hline \multirow{2}{*}{$\boldsymbol{m}_{\boldsymbol{a}}=\mathbf{0 . 1}$} & $\mathrm{THD}, \%$ & 36.53 & 120.39 & 105.99 \\
& $\mathrm{~V} / \mathrm{m}, \mathrm{V}$ & 1452 & 415.6 & 478.6 \\
\hline
\end{tabular}

\section{Cross-Bridge Multilevel Inverter Topology}

By utilizing the ideas of ordinary cascade H-bridge and the multi-string staggered inverter, the seven-level cross-exchanged staggered inverter geography $[2,6,16,17]$ is planned. This geography comprises of six force semiconductor switches and two DC voltage sources. The switches are addressed as $\mathrm{S}_{1}, \mathrm{~S}_{2}, \mathrm{~S}_{3}, \mathrm{~S}_{4}, \mathrm{~S}_{5}$, and $\mathrm{S}_{6}$, while the DC sources are addressed as $E_{1}$ and $E_{2}$. From Fig. 10 two switches $\left(\mathrm{S}_{5} \& \mathrm{~S}_{6}\right)$ are available in the center and as they are sharing the voltage from both DC sources, they have the most noteworthy voltage appraisals. A proportion of $2: 1$ is kept up with by DC sources which infer unbalanced setup. From Fig. 10 the switches $\mathrm{S}_{1} \& \mathrm{~S}_{2}$ which are near to the source $E_{1}$ will have a voltage rating of $2 \mathrm{~V}_{\mathrm{dc}}$ and they contribute to generate voltage levels $-\mathrm{V}_{\mathrm{dc}}$, $0,2 V_{\mathrm{dc}}$. Similarly, the switches $\mathrm{S}_{3} \& \mathrm{~S}_{4}$ which are near to source 2 will have a voltage rating of $V_{\mathrm{dc}}$ and they contribute to generate three voltage levels $-\mathrm{V}_{\mathrm{dc}}, 0,+\mathrm{V}_{\mathrm{dc}}$. The middle switches $S_{5} \& S_{6}$ will produce $+3 V_{d c} \&-3 V_{d c}$ respectively.

Total seven output voltage levels $-3 \mathrm{~V}_{\mathrm{dc}},-2 \mathrm{~V}_{\mathrm{dc}},-\mathrm{V}_{\mathrm{dc}}, 0$, $\mathrm{V}_{\mathrm{dc}}, 2 \mathrm{~V}_{\mathrm{dc}}, 3 \mathrm{~V}_{\mathrm{dc}}$ are generated. Also, the odd-numbered switches operate in a complementary manner to the evennumbered switches. Table 6 shows the switching sequences of the proposed topology.

By extending this to more levels the voltage capacity of the inverter can be increased. So, this proposed topology can be extended to N-levels by using the below formulae:

$$
\begin{aligned}
& \mathrm{N}_{\text {Switch }}=\mathrm{N}_{\text {Level }}-1 \\
& \mathrm{~N}_{\text {DC_supplies }}=\mathrm{N}_{\text {Switch }} / 3
\end{aligned}
$$

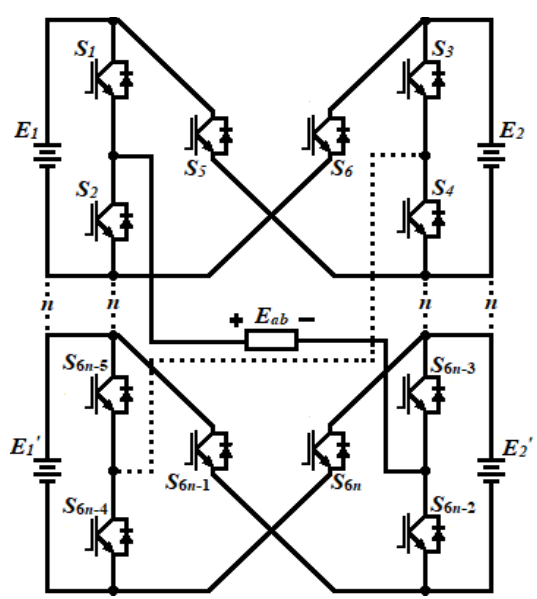

Fig. 10. Single-phase N-level cross switch multilevel inverter [1]

Table 6. Switching sequences of 7-level cross switch multilevel

\begin{tabular}{|c|c|c|c|c|c|}
\hline \multicolumn{3}{|c|}{ Switching States } & \multicolumn{2}{|c|}{$\begin{array}{c}\text { DC Supply } \\
\text { Voltages }\end{array}$} & \multirow{2}{*}{$\begin{array}{c}\begin{array}{c}\text { Total } \\
\text { Voltage }\end{array} \\
\mathbf{E}_{\mathbf{a b}} \\
\end{array}$} \\
\hline $\mathbf{S}_{1}$ & $S_{5}$ & $\mathbf{S}_{3}$ & $E_{1}$ & $\mathbf{E}_{2}$ & \\
\hline 1 & 0 & 0 & $2 V_{d c}$ & $\mathrm{~V}_{\mathrm{dc}}$ & $3 \mathrm{~V}_{\mathrm{dc}}$ \\
\hline 1 & 1 & 0 & $2 V_{d c}$ & 0 & $2 V_{d c}$ \\
\hline 0 & 0 & 0 & 0 & $\mathrm{~V}_{\mathrm{dc}}$ & $\mathrm{V}_{\mathrm{dc}}$ \\
\hline 0 & 1 & 0 & 0 & 0 & 0 \\
\hline 1 & 0 & 1 & 0 & 0 & 0 \\
\hline 1 & 1 & 1 & $-2 V_{d c}$ & $\mathrm{~V}_{\mathrm{dc}}$ & $-\mathrm{V}_{\mathrm{dc}}$ \\
\hline 0 & 0 & 1 & $-2 V_{d c}$ & 0 & $-2 V_{d c}$ \\
\hline 0 & 1 & 1 & $-2 V_{d c}$ & $-\mathrm{V}_{\mathrm{dc}}$ & $-3 \mathrm{~V}_{\mathrm{dc}}$ \\
\hline
\end{tabular}
inverter

\subsection{Control of Cross-Bridge using Sinusoidal Pulse Width Modulation (SPWM)}

The sinusoidal pulse width modulation technique $[2,6,16,17]$ is used to generate the gate pulses and sevenlevel output of the cross switch multilevel inverter. The carrier wave modulation technique is one of the types of SPWM, which is again divided into two types i.e., phaseshifted carrier modulation (PSCM) and level shifted carrier modulation (LSCM). In this paper, we are considering the LSCM technique as it has advantages like low harmonics and more flexibility to operate inverter at different switching frequencies compared to PSCM. Here, phase opposition disposition (POD) is used to generate the six carrier waves. Where carrier waves above the zero reference are in phase among each other whereas out of phase to those below the zero references. Six carrier waves $\mathrm{V}_{\mathrm{cr} 2}, \mathrm{~V}_{\mathrm{cr} 3}, \mathrm{~V}_{\text {-cr1 }}, \mathrm{V}_{\text {-cr2}}$, and $\mathrm{V}_{\text {-cr3 }}$ as shown in Fig. 10 are required for cross switch topology as it generates seven output voltage levels. An amplitude of $A_{c r}$ and frequency of $f_{c r}$ are possessed by each carrier wave. Whereas the sinusoidal reference voltage $\mathrm{V}_{\mathrm{ab}}$ ref is having a frequency of $50 \mathrm{~Hz}$ and amplitude of 1 to 
generate the signal pulse. Thus, the frequency modulation and amplitude modulation indices are given below:

$m_{f}=\frac{f_{c r}}{f}$
$m_{a}=\frac{A_{m}}{A_{c r} \times \frac{N_{\text {level }}-1}{2}}$

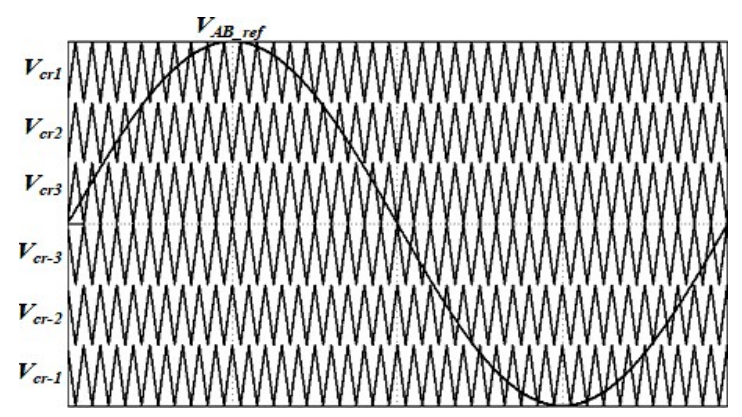

Fig.11. SPWM using carrier waves following level-shifted POD [2].

The block diagram in Fig. 12 gives the control and implementation of SPWM. In this technique, carrier waves are compared with the sinusoidal reference wave. If the modulating wave (reference) is greater than the positive carrier waves, then the output of ' 1 ' else ' 0 ' will be obtained. On adding the pulses $(P l)$ obtained from the above comparisons we will get the switching states (SW) as below:

$\mathrm{SW}=\left(\mathrm{Pl}_{1}+\mathrm{Pl}_{2}+\mathrm{Pl}_{3}\right)+\left(\mathrm{Pl}_{-1}+\mathrm{Pl}_{-2}+\mathrm{Pl}_{-3}\right)$

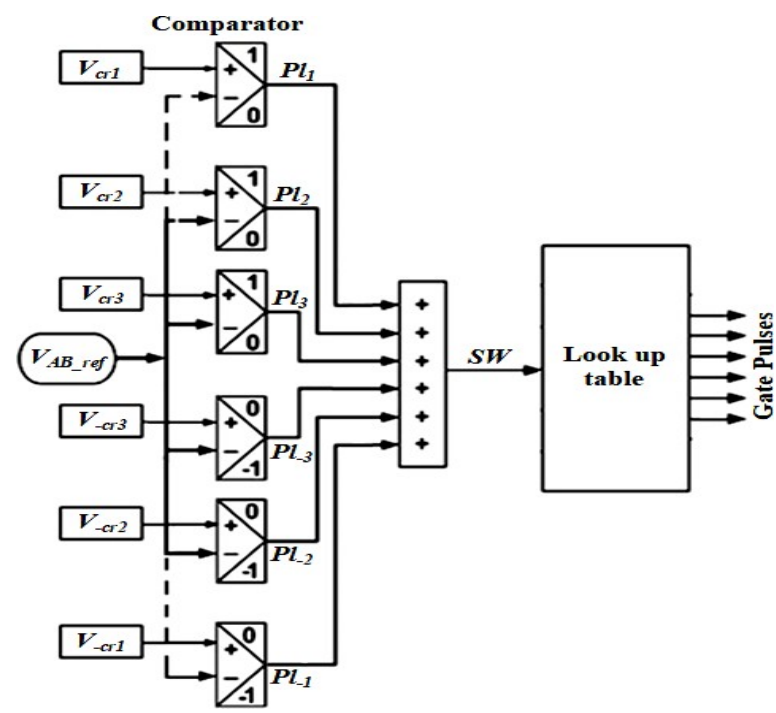

Fig. 12. The control diagram of the SPWM technique for crossswitched MLI [2].

On comparing switching states with the lookup table, we will get six gate pulses and these pulses are used by the multilevel inverter to generate output seven-level voltage. The harmonic distortions in Fig. 13 are obtained by taking $\mathrm{E}_{1}=66.67 \mathrm{~V}_{\mathrm{dc}}$ and $\mathrm{E}_{2}=33.33 \mathrm{~V}_{\mathrm{dc}}$ and considering R$\mathrm{L}$ load $(\mathrm{R}=237 \Omega, \mathrm{L}=0.53 \mathrm{H})$ the simulation results are obtained. From the below results we can say that as the modulation ratio is decreased, the output and RMS voltages are reduced. As a result, fewer numbered output steps are obtained, and total harmonic distortion (THD) got increased as the inverter is generating a lower number of steps.

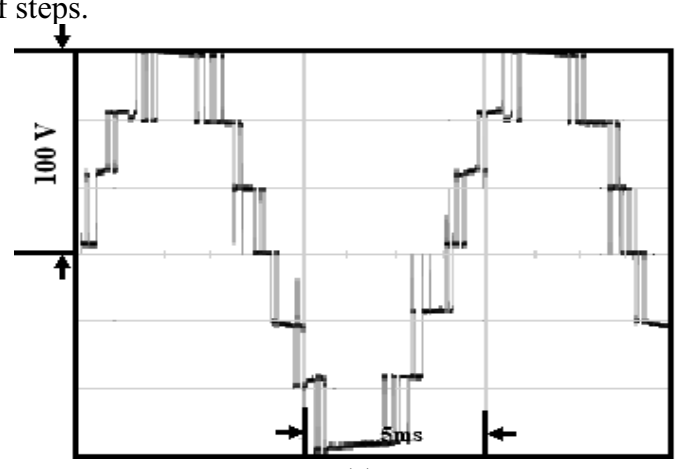

(a)

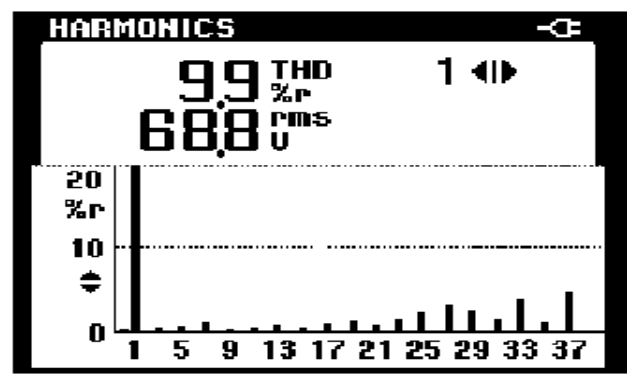

(b)

Fig. 13. Experimental results at $m=1$ for SPWM [2]:

(a) 7-level output voltage

(b) THD and RMS voltage.

\subsection{Control of Cross-Bridge using Space Vector Pulse Width Modulation (SVPWM)}

In the proposed multilevel inverter topology we use one-dimensional SVPWM control $[1,6,16,17]$ over conventional control. As the conventional SVPWM techniques involve complex mathematical calculations and also due to its large switching states. $E_{1}$ and $E_{2}$ of the given cross switched topologies give $-2 \mathrm{~V}_{\mathrm{dc}}, 0,2 \mathrm{~V}_{\mathrm{dc}}$, and $\mathrm{V}_{\mathrm{dc}}, 0, \mathrm{~V}_{\mathrm{dc}}$ respectively and whose voltage levels are represented as $0,1,2$ in this control region. In Fig. 14 the state $\mathrm{XY}$ corresponds to the cross switch inverter having states $X \& Y$ represents $E_{1} \& E_{2}$ supplies respectively.

Fig. 15 shows the stream chart which utilizes the necessary numerical computations in one-dimensional control to acquire exchanging arrangements and exchanging times. Here the sinusoidal wave with recurrence $50 \mathrm{~Hz}$ and modulation index $=1$ is chosen as reference voltage $V_{a b}$ ref. The reference voltage $V_{a b}$ ref is standardized with $\overline{D C}$ voltage step $\mathrm{V}_{\mathrm{dc}}$ to acquire the positive reference voltage 'a'. The contrast between two continuous voltage levels is called step and it is consistently steady which can be found in Fig. 14. The capacity floor ' $a$ ' rounds of the components of 'a' to its closest number which is not exactly or equivalent to 'a' to decide the 'simulated intelligence' factor. Hence, acquired whole number variables are utilized to decide exchanging states and times. Always the switching sequences formed 
by the switching states $\mathrm{S}_{1}=\mathrm{a}_{\mathrm{i}}, \mathrm{S}_{2}=\mathrm{a}_{\mathrm{i}}+1$ with switching times $t_{1}=1-r \& t_{2}=r$ respectively. Thus, the final switching sequence ' $\mathrm{S}_{\mathrm{p}}$ ' is determined by comparing $\mathrm{S}_{\mathrm{p}}$ repeatedly with the lookup table we will obtain seven gate pulses and then these are used for switches of multilevel inverter.

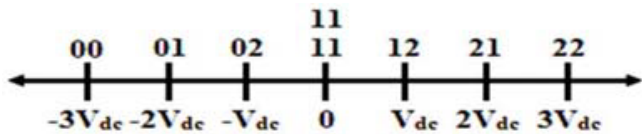

Fig. 14. One dimensional control region for seven-level crossswitched MLI [1].

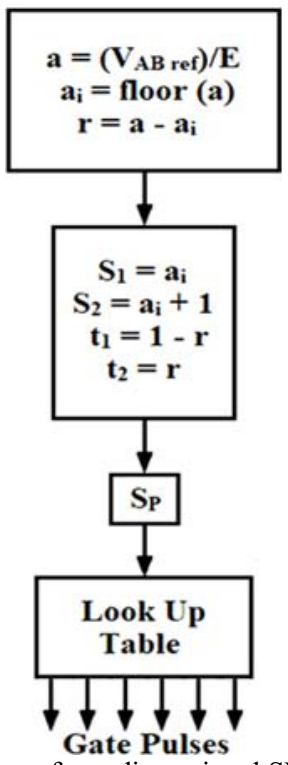

Fig. 15. Flow diagram of one dimensional SVM control of single-phase [1]

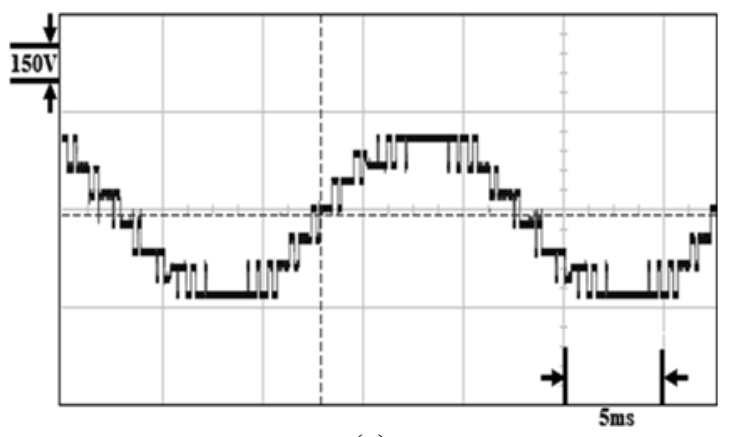

(a)

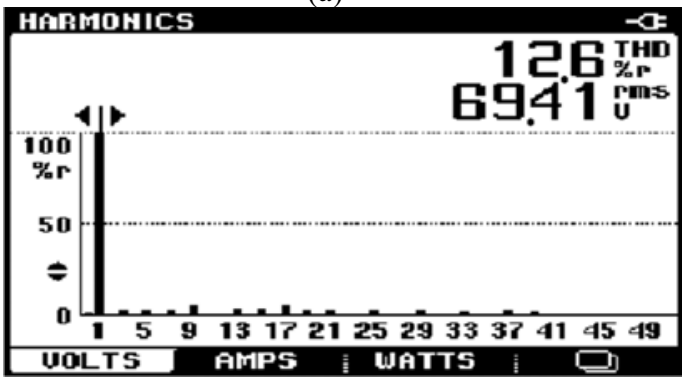

(b)

Fig.16. Experimental results of SVPWM for the cross-switched MLI [1].

(a) Seven steps output voltage at $m=1$.

(b) THD and RMS voltage at $m=1$
The harmonic distortions in the below Fig. 16 are obtained by taking $\mathrm{E}_{1}=66.67 \mathrm{~V}_{\mathrm{dc}}$ and $\mathrm{E}_{2}=33.33 \mathrm{~V}_{\mathrm{dc}}$ and considering R-L load $(\mathrm{R}=237 \Omega, \mathrm{L}=0.53 \mathrm{H})$ the simulation results are obtained. From the below results we can say that as the modulation ratio is decreased, the output and RMS voltages are reduced. As a result, fewer numbered output steps are obtained, and total harmonic distortion (THD) got increased as the inverter is generating a lower number of steps.

Table 7. Comparison of SVPWM and SPWM control techniques for seven-level cross-bridge inverter

\begin{tabular}{|c|c|c|c|}
\hline $\begin{array}{c}\text { Modulation } \\
\text { Technique }\end{array}$ & $\begin{array}{c}\text { Space vector } \\
\text { pulse width } \\
\text { modulation } \\
\text { (SVPWM) }\end{array}$ & $\begin{array}{c}\text { Sinusoidal } \\
\text { pulse width } \\
\text { modulation } \\
\text { (SPWM) }\end{array}$ \\
\hline \multirow{2}{*}{$\mathbf{m}_{\mathbf{a}}=\mathbf{1 . 0}$} & $\begin{array}{c}\mathrm{THD}, \% \\
\mathrm{~V}_{\text {rms }}\end{array}$ & 12.6 & 9.9 \\
\hline \multirow{2}{*}{$\mathbf{m}_{\mathbf{a}}=\mathbf{0 . 8}$} & $\begin{array}{c}\mathrm{THD}, \% \\
\mathrm{~V}, 41\end{array}$ & 19.4 & 68.8 \\
\hline & $\mathrm{V}_{\text {rms }}$ & 45.17 & 54.7 \\
\hline
\end{tabular}

\section{Comparison of a cross switch and cascaded $\mathrm{h}$-bridge multilevel inverters}

Here the acquired outcomes from the over seven-level cross-connect geography are contrasted and symmetric cascade H-connect geography. Five elements are thought about for the correlation of both the geographies. They are the quantity of switches, power misfortune, Total Standing Voltage(TSV) of influence semiconductor gadgets, at any moment the quantity of gadgets in the current way, and all total harmonic distortion(THD).

Table 8 shows the examination of the quantity of switches for fell $\mathrm{H}$-extension and cross-connect inverters for 7,9,15 and 21 levels individually. From Table 8, we can infer that cross switch geography utilizes a lower number of switches contrasted with fell H-connect geography. As the quantity of switches is diminished importantly driver circuits required and intricacy can likewise be decreased in cross switch staggered inverter contrasted with fell H-connect.

Fig. 17 shows that the total standing voltage(TSV) of both cascaded and cross-bridge inverters are the same for seven-level or any other greater levels of multilevel inverters. Mathematically we can see from the below formulae:

$\left(\mathrm{TSV}_{\text {cross }} / \mathrm{V}_{\mathrm{dc}}\right)=2\left(\mathrm{~N}_{\mathrm{l}}-1\right)$ and

$\left(\mathrm{TSV}_{\text {cascaded }} / \mathrm{V}_{\mathrm{dc}}\right)=\left(\mathrm{TSV}_{\text {cross }} / \mathrm{V}_{\mathrm{dc}}\right)$

Thus the Fig.18 shows the cross-switch topology has fewer series devices as compared to cascaded H-bridge topology in the current path, which implies that the voltage drops, and conduction losses of a cross switch are less compared to cascade. The number of switches in the current path of seven-level cross-switch topology is 4 , whereas in cascaded H-bridge is 6 . For N-levels $\left(N_{l}\right)$ we can find the number of switches in the current path $\left(N_{d}\right)$ by using the below formulae: 
$N_{d}$, cross $=\frac{N_{l}+1}{2}$

$N_{d}, C H B=N_{l}-1$

Another factor of comparison is power losses. From Fig. 19 the cross-bridge topology has lower losses than cascaded H-bridge topology. This is because cross-bridge topology is having lower devices in the current path at any instant of time.

Table 8. Comparison of the number of switches for cascaded and cross-bridge inverters.

\begin{tabular}{|c|c|c|c|c|}
\hline $\begin{array}{c}\text { Cascaded } \\
\text { H-bridge } \\
\text { inverter } \\
\text { level }\end{array}$ & $\begin{array}{c}\text { Number } \\
\text { of } \\
\text { switches }\end{array}$ & Diodes & $\begin{array}{c}\text { DC } \\
\text { sources }\end{array}$ & $\begin{array}{c}\text { Total } \\
\text { compo } \\
\text { nents }\end{array}$ \\
\hline 7 & 12 & 12 & 3 & 27 \\
\hline 9 & 16 & 16 & 4 & 36 \\
\hline 15 & 28 & 28 & 7 & 63 \\
\hline 21 & 40 & 40 & 10 & 90 \\
\hline $\begin{array}{c}\text { Cross } \\
\text { bridge } \\
\text { inverter } \\
\text { level }\end{array}$ & $\begin{array}{c}\text { Number } \\
\text { of } \\
\text { switches }\end{array}$ & Diodes & $\begin{array}{c}\text { DC } \\
\text { sources }\end{array}$ & $\begin{array}{c}\text { Total } \\
\text { compo } \\
\text { nents }\end{array}$ \\
\hline 7 & 6 & 6 & 2 & 14 \\
\hline 9 & 8 & 8 & 3 & 19 \\
\hline 15 & 14 & 14 & 5 & 33 \\
\hline 21 & 20 & 20 & 7 & 47 \\
\hline
\end{tabular}

\section{cascaded H-bridge , cross bridge}

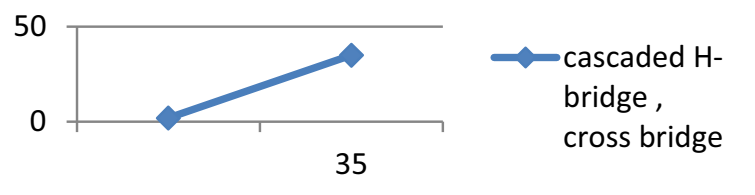

Fig. 17. The total standing voltage of switches against the number of voltage levels $\left(\mathrm{N}_{1}\right)$ in cascaded H-bridge and crossbridge topologies

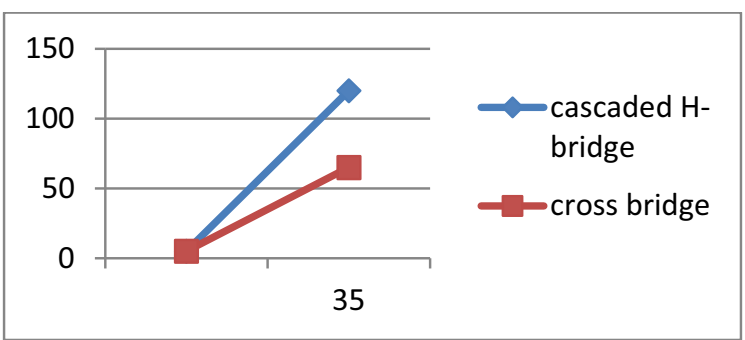

Fig. 18. Number of switches in the current path $\left(\mathrm{N}_{\mathrm{d}}\right)$ against the number of voltage levels $\left(\mathrm{N}_{1}\right)$ in cascaded $\mathrm{H}$-bridge and crossbridge topologies

The total harmonic distortion (THD) factor can likewise be thought of while contrasting both seven-level fell $\mathrm{H}$ extension and cross-connect. From Table 5 we can infer that the third harmonic distortion gives low harmonic for modulation index more noteworthy than 0.2 and the FSSVPWM method gives lower music for regulation list lesser than 0.2. Essentially, from Table 7, we can presume that the SPWM procedure gives lower music contrasted with the SVPWM strategy for the proposed seven-level cross switch geography. These outcomes apply to any more significant level inverters individually. On the off chance that we look at traditional geographies, we can presume that cross-connect geography will have lower symphonious mutilations contrasted with fell $\mathrm{H}$ connect. The upsides of cascade H-bridge geography over cross-connect are its accessibility of adaptation to internal failure i.e., if one of the H-spans is broken even, it tends to be skirted, and other H-spans supply the load.

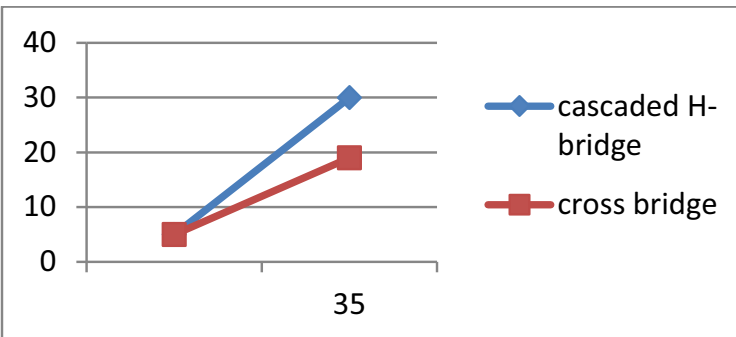

Fig. 19. Switching losses ( $\left.\mathrm{P}_{\text {loss }}\right)$ against the number of voltage levels $\left(\mathrm{N}_{1}\right)$ in cascaded $\mathrm{H}$-bridge and cross-bridge topologies

\section{Conclusion}

In this paper different control techniques, which are sinusoidal pulse width modulation, space vector pulse width modulation, third harmonic injection pulse width modulation are discussed and compared. From these control techniques we can conclude that for low total harmonic distortions, third harmonic injection pulse width modulation is considered over the other two. For modulation indices less than or equal to 0.2 and for better fundamental voltage we use space vector pulse width modulation techniques respectively for seven-level cascaded H-bridge. Additionally, we can presume that the SPWM method gives lower music contrasted with the SVPWM strategy for the proposed seven-level cross switch geography. Likewise in this paper, we analyzed cascade H-bridge and cross-connect topologies for various levels for the variables: number of switches, absolute standing voltage, and number of switches in the current way at any moment, power misfortunes, and complete consonant twists. It tends to be reasoned that cross-switch topology performs better compared to cascade H-bridge topology particularly when there is a restriction in the quantity of switches. The cross-switch geography doesn't utilize high voltage switches and consequently it tends to be utilized for high voltage applications. As there are fewer switches in the current path in cross switch topology, the switching losses are also low compared to the cascaded H-bridge topology.

\section{Acknowledgement}

Authors would like to thank All India Council for Technical Education (AICTE), Govt. of INDIA for sanction of grants under Research Promotion Scheme (RPS). Grant Number: 8-174/RIFD/RPS(Policy-1)/201819 dt: 22 Nov 2019. 


\section{References}

1. Sheikh Tanzim Meraj, Kamrul Hasan, Ammar Masaoud, (2017).

2. Sheikh Tanzim Meraj, Law Kah Haw, Ammar Masaoud, (CSPA 2019).

3. Irfan Ahmed, Vijay B. Borghate, (IET Power Electronics, 2013).

4. Ilhami Colak, Ramazan Bayindir, Ersan Kabalci, $A$ Modified Harmonic Mitigation Analysis Using Third Harmonic Injection PWM in a Multilevel Inverter Control (EPE-PEMC 2010).

5. B. J. Varghese, P. B. Bobba and M. Kavitha, Effects of coil misalignment in a four coil implantable wireless power transfer system, (IEEE PIICON 2016).

6. Mohammad Farhadi Kangarlu, Ebrahim Babaei, IET Power Electro., 12, 8 (2013)

7. G. Uma Devi, P. Manikandan, A. Themo Theu, S. Prabakaran, (July 2013).
8. Patil Swapnil Sanjay, Patil Rupali Anaji, Patil S.K, Symmetrical Multilevel Cascaded H Bridge Inverter Using Multicarrier SPWM Technique,(2018).

9. J. Srinivas Rao, P. Srinivasa Varma, T. Suresh Kumar, Int. Jol. of Power Electronics and Drive Systems 9, 3 (2018).

10. Nikhil Agarwal, Praveen Bhansal, (RDCAPE, 2017).

11. B. Phani Teja, V. Srikanth Babu, T. Suresh Kumar, Int. Jol. of App. Engg. Research 10, 16 (2015).

12. C Dhanamjayalu, S Meikandasivam, (I-PACT, 2017).

13. M. Kavitha, P. B. Bobba and D. Prasad, Investigations and experimental study on Magnetic Resonant coupling based Wireless Power Transfer system for neighborhood EV's, (IEEE ICPS 2016).

14. Basem Alamri, Saeed Alsharani, Mohamed Darwish, (UPEC, 2015).

15. Kavitha Merugu, Prasad Dinkar, Bobba Phaneendra Babu, IET Electric Power Appl., 13, 8 (2019).

16. Ebrahim Babaei, Mohammad Farhadi Kangarlu, Mehran Sarabhi, IET Power Electro., 14, 6 (2014).

17. T.Tarezewski, L.M.Grzesiale, (EPE, 2013) 